\title{
Midwifery Students' Confidence in New-Born Care at Completion of Training in Selected Midwifery Schools in Zambia. A Multicentric Study: A Case of Zambia
}

\author{
Brenda Nambala Sianchapa, Mutinke Zulu, Concepta Kwaleyela, Margaret C. Maimbolwa \\ School of Nursing Sciences, University of Zambia, Lusaka, Zambia \\ Email: address brenda.sianchapa@unza.zm
}

How to cite this paper: Sianchapa, B.N., Zulu, M., Kwaleyela, C. and Maimbolwa, M.C. (2020) Midwifery Students' Confidence in New-Born Care at Completion of Training in Selected Midwifery Schools in Zambia. A Multicentric Study: A Case of Zambia. Health, 12, 972-997.

https://doi.org/10.4236/health.2020.128073

Received: July 4, 2020

Accepted: August 14, 2020

Published: August 17, 2020

Copyright $\odot 2020$ by author(s) and Scientific Research Publishing Inc. This work is licensed under the Creative Commons Attribution International License (CC BY 4.0).

http://creativecommons.org/licenses/by/4.0/

\begin{abstract}
Background: Quality education is one of the important factors in empowering midwives to provide quality health care services to mothers and newborns irrespective of their practice settings. Due to lack of standardization of the duration, content, and structure of midwifery education and different pathways to midwifery across the world, midwives may lack the confidence to deliver quality health care services in the main domain of the ICM competences. Aim: To assess the confidence of final year midwifery students in the domain of new-born care based on the ICM midwifery competencies. Methods: The first phase consisted of a quick situation analysis of midwifery education and regulation in Zambia, followed by a cross-sectional survey through a selfadministered questionnaire to assess the confidence of final year midwifery students. Results: Most (51.9\%) of the respondents were aged between 18 and 28 years, and majority of them were placed in Levels 1, 2 and 3 Hospitals and also clinics for their clinical practice, with between one hundred to ten thousand annual births, followed by $16.9 \%$ who were placed in Level 3 hospitals only. Most students (38.3\%) reported receiving classroom instruction by both Lecture and Demonstration. Few students $(22.7 \%)$ responded that they were not satisfied with their clinical supervision, while $77.3 \%$ were satisfied. There was significant association between confidence to perform skills independently and having enough time to practice on models in the labs ( $\mathrm{p}$ value $=$ 0.024 ), confidence when practiced for the first time on mothers ( $\mathrm{p}$ value $=$ 0.007 ) and satisfaction with supervision during clinical practice ( $\mathrm{p}$ value $=$ 0.000). Binary logistic regression of characteristics associated with confidence to perform new-born skills independently revealed significant association between satisfaction with clinical supervision and confidence to perform
\end{abstract}


skills independently, 95\% CI [1.83, 15.37]. Conclusion: Midwifery students need quality training both theoretically and practically in order for them to gain confidence in newborn care upon completion of their training. They need adequate time to practice on models in the skills laboratory, and need adequate clinical supervision for them to gain confidence in performing new born skills independently.

\section{Keywords}

Confidence, New Born Care, Midwifery Students

\section{Introduction}

Newborn care is the care that is given to a newborn baby after delivery. This care is dependent upon the competence of the birth attendant who, in most cases is a midwife. If adequately cared for, newborn babies are able to transition successfully from intrauterine to extrauterine life. The quality of care given may determine the survival of a newborn baby, especially the one that may need resuscitative measures at birth. Midwives should be competent in order for them to adequately care for the newborn babies under their care.

This multi-centric study is a development from an earlier study which was conducted in one province of India by Sharma in 2014. This study utilized the essential midwifery competencies of the International Confederation of Midwives (ICM) to assess the confidence of final-year midwifery students on competencies in the domains of antepartum, intrapartum, postpartum and newborn care [1]. The findings of the Indian study showed a general low confidence among final-year students in all the four domains of midwifery competencies. In the domain of intrapartum care, students expressed less confidence in basic skills such as assessing the uterine contractions during labour, to detecting and dealing with intrapartum complications [1]. The low confidence was associated with having inadequate clinical practice during their basic midwifery training.

The findings of the Indian study were presented to the ICM and the World Health Organization (WHO) who expressed interest in having similar quality assessments in other countries. Although there has been a lot of discussion on the need to improve the quality of midwifery education, there are very few studies, which show where the short comings are and what needs to be improved. Findings from such assessments could be used for advocacy with respective governments with the view of improving the basic education of midwives.

Zambia is one of the countries that agreed to participate in the study. This study therefore determined the confidence of Midwifery students in newborn skills upon completion of their training in selected Midwifery schools in Zambia

\subsection{Background}

Quality education is one of the important factors empowering midwives to pro- 
vide quality health care services to mothers and newborns irrespective of their practice settings. Due to lack of standardization of the duration, content, and structure of midwifery education and different pathways to midwifery across the world, midwives may lack the confidence to deliver quality health care services in the main domain of the ICM competences.

Zambia offers midwifery education in 13 schools. Of these schools, 8 offer a post basic certificate in midwifery to nurses who have already been trained for 3 years in general nursing. The other 5 schools offer midwifery education to school leavers. Three of these schools offer a two year midwifery training program and graduates get a certificate in midwifery. The other 2 offer a three and half years nursing and midwifery training and students graduate with a Diploma in nursing and midwifery. The pass rate in most of the midwifery training institutions has been high.

The total number of midwifery schools and the pass rates are as displayed in Table 1 and Table 2 respectively.

Zambia also offers midwifery education at University level to students who are pursuing their Bachelor's degree in Nursing, Master's degree in Nursing, and from 2018, the University of Zambia has started offering a Bachelor of Science in Midwifery. In 2015, a PhD program in Midwifery was introduced at the University of Zambia, funded by Norwegian Programme for Capacity Development in Higher Education and Research for Development (NORHED) [2].

Introduction about the Country (Overview)

Zambia' total population was estimated to be about 13.1 million during the 2011

Table 1. Midwifery schools in Zambia.

\begin{tabular}{cc}
\hline Qualifications offered & Number of schools \\
\hline Certificate in midwifery & 8 \\
Certificate in midwifery (direct entry) & 3 \\
Diploma in nursing and midwifery & 2 \\
TOTAL & 13 \\
\hline
\end{tabular}

Source: General Nursing Council of Zambia, 2015.

Table 2. Midwifery passrates from 2010 to 2015 .

\begin{tabular}{ccccc}
\hline Year & $\begin{array}{c}\text { Total Number of Midwifery Students } \\
\text { who sat for the examinations }\end{array}$ & $\begin{array}{c}\text { Total Number of Students } \\
\text { who Passed Final Exam }\end{array}$ & $\begin{array}{c}\text { Pass } \\
\text { Rate (\%) }\end{array}$ & $\begin{array}{c}\text { Failure } \\
\text { rate (\%) }\end{array}$ \\
\hline 2015 & 246 & 213 & 86.58 & 13.42 \\
2014 & 302 & 280 & 92.71 & 7.3 \\
2013 & 233 & 224 & 96.13 & 3.87 \\
2012 & 297 & 286 & 92.29 & 7.71 \\
2011 & 280 & 268 & 95.71 & 4.29 \\
2010 & 223 & 206 & 92.37 & 7.63 \\
\hline
\end{tabular}

Source: General Nursing Council of Zambia (2015). 
national census and a population growth rate of $3 \%$ per annum [3]. The estimated total fertility rate was 5.9 births per woman in 2010 with a life expectancy at birth of 49 years for males and 53 years for females [3].

The Total Fertility Rate for the three years preceding the 2013-14 ZDHS was 5.3 births per woman. Fertility was considerably higher in rural areas (6.6 births per woman) than in urban areas ( 3.7 births per woman), with child bearing that starts early at 13 years. The median birth interval in Zambia was 35 months, ranging from 25 months among mothers aged 15 - 19 to 40 months among mothers age 40 - 49 years. There was no marked difference in the length of the median birth interval by birth order or sex of the preceding birth. Injectable are the most widely used modern methods of contraception (19\%) among currently married women, followed by the pill (12\%), implants (6\%), and the male condom which is at $4 \%$ [3].

One in every 22 children dies before reaching age one (1) and one in every 13 does not survive to his or her $5^{\text {th }}$ birthday. The neonatal mortality rate is 24 deaths per 1000 live births. The perinatal mortality rate is 31 per 1000 pregnancies. These mortality rates can be reduced if competent midwives monitor the health of the women during pregnancy, labour and delivery and the postnatal period. Zambia, through its Ministry of Health $(\mathrm{MoH})$ is putting efforts to curb these mortality rates by training more midwives to increase on the provision of skilled care to women in the childbearing age [4].

About $96 \%$ of mothers received antenatal care from a skilled provider (a doctor, clinical officer, nurse, or midwife) during their most recent birth in the five years which preceded the survey. Most of these received focused antenatal care which Zambia has been providing since 2002 [5]. About $91 \%$ of the pregnant women discussed birth preparedness with their health care providers and about $82 \%$ used the birth plan. About $67 \%$ of births took place in a health facility, while home deliveries comprised of $31 \%$.

Health facility deliveries are common among births to mothers less than age $20(74 \%)$ and first-order births (81\%). Births in urban areas are more likely (89\%) to occur in health facilities than births in rural areas (56\%). The level of skills of the provider who performs the first postnatal check-up also has important implications for maternal and neonatal health. About 53\% of women received postnatal care from a nurse or midwife, $5 \%$ from a doctor, and $1 \%$ from a clinical officer. Only $3 \%$ of the women received postnatal care from a traditional birth attendant [3]. Antepartum, Intrapartum and Postpartum coverage in Zambia is as shown in Table 3.

With a neonatal mortality rate of 24/1000 live births and a perinatal mortality rate of 31/1000 pregnancies [4], it is important to find out whether these deaths could be attributed to the care that the women received during pregnancy, labour and delivery. This study was therefore conducted to determine midwifery students' confidence in newborn skills at completion of their training

\subsection{Statement of the Problem}

Zambia has been training midwives, from the early 1960s. In the recent years, a 
Table 3. Antepartum, Intarpartum and Postparum coverage in Zambia.

\begin{tabular}{lc}
\hline \multicolumn{1}{c}{ Indicator } & Percentage \\
\hline Received antenatal care from skilled provider & $96 \%$ \\
Discussed birth preparedness with health care provider & $91 \%$ \\
Used the birth plan & $82 \%$ \\
Births that took place in health facility & $67 \%$ \\
Births that took place in health facilities in women aged less than 20 years & $74 \%$ \\
First order births that took place in health facility & $81 \%$ \\
Births that took place in health facility in urban areas & $89 \%$ \\
Births that took place in a health facility in rural areas & $56 \%$ \\
Home deliveries & $31 \%$ \\
Received postnatal care from a nurse/midwife & $53 \%$ \\
Received postnatal care from a doctor & $5 \%$ \\
Received postnatal care from a clinical officer & $1 \%$ \\
Received postnatal care from a traditional birth attendant & $3 \%$ \\
\hline
\end{tabular}

SOURCE: CSO, MoH, ICF (2015).

deliberate move has been made to increase the number of midwives by opening more midwifery training institutions [6]. In spite of all these efforts, maternal and neonatal mortality rates continue to be on the higher side.

The neonatal mortality rate (NMR) is 24 deaths per 1000 live births, perinatal mortality rate (PMR) is 31 per 1000 pregnancies and maternal mortality rate $389 / 100,000$ live births [3]. These statistics could be an indication of the quality of maternity care that is provided by midwives.

\subsection{Study Justification}

In order to provide quality midwifery care to clients, it is vital that midwives acquire the necessary competences for practice. The midwives also need to have confidence in the domains of antepartum, intrapartum, postpartum, and new-born care from the list of midwifery competencies as stipulated by the ICM. In spite of the high pass rates among student midwives, it is not known how confident the students are in new born care competences at the end of their training.

There is little information about studies done to assess confidence among final year midwifery students in Zambia. The proposed study is intended to provide specific feed back to the midwifery training program, policy makers and other stakeholders on areas that need to be strengthened. This will in turn improve midwifery education and quality of midwifery care provided to mothers and their babies

\subsection{Conceptual Framework}

\subsubsection{Confidence and Competence}

Concepts of confidence and competence may be linked but are not synonymous. 
Confidence as defined by the oxford dictionary is "A feeling of self-assurance arising from an appreciation of one's own abilities or qualities". Competence is on the other hand "the ability to do something successfully or efficiently".

Confidence has three influencing attributes; it is situational (depends on available time and resources), institutional (structure and pedagogy of educational programmes) and dispositional (personal traits-attitudes, and motivation) [7]. Therefore increased level of confidence is not in direct proportion to increased competence, although decreased confidence may be linked to a reduction in skilled performance [8].

According to Bandura (1977), confidence is the strength of self-efficacy [9]. "Self-efficacy" or self-regulation is an important attribute of competency having three dimensions; confidence level (magnitude, or difficulty of tasks the individuals think they can perform) and generalizability (extent of transfer to other areas of functioning) [9]. When applied to the midwife, confidence would concern task performance and perseverance when confronting difficulties and setbacks in the work situations. Butler et al. (2006) identified "being a safe practitioner" as one of the essential competencies required of a midwife at the point of registration [10]. Being a safe practitioner included the ability to detect deviations and take appropriate action, and respond to emergency situations [11]. Poor performance and lack of confidence among newly qualified nurses was found to be a direct consequence of pre-registration programmes lacking practice-based training [12]. Norman and colleagues found a number of factors which facilitated confidence many of which emphasize student-teacher relationships such as; Learning, experiencing and achieving, feeling secure and receiving positive feedback, familiarity and receiving support and encouragement, working with staff at the teaching practice placement, and being treated well [7].

To summarize, confidence for the midwife concerns with; task performance and perseverance in difficult situations [9], and being a safe practitioner, which means recognizing their personal ability, and awareness of their personal limitations when they need to ask for appropriate help [12].

Further, confidence is influenced by the quality of structured experience provided in the learning environment facilitated by positive and encouraging relationships between the teacher and the learner [7]. Therefore one can say that, there exists a relationship between confidence and competence (though complex); confidence seems to be a mediating factor for achieving and demonstrating competence and partially predicting performance (Figure 1). For this study, measuring confidence could reflect the quality of teaching-learning experience the midwifery educational institutions are able to provide to their students, and could also help to assess their ability to practice as confident and competent midwives.

\subsection{Study Objectives}

\subsubsection{General Objective}

To assess the confidence of final year midwifery students in the domain of 


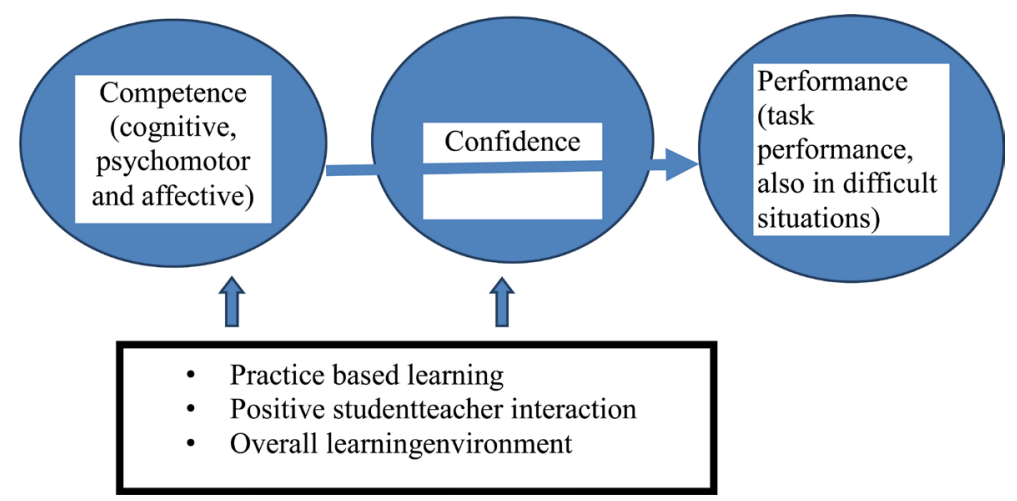

Source. Sharma, 2014.

Figure 1. Relationship between confidence, competence and performance.

new-born care based on the ICM midwifery competencies.

\subsubsection{Specific Objectives}

1) Assess the relationship between student's socio demographic characteristics and confidence in the domains of new-born care based on the ICM midwifery competencies.

2) Identify areas in the domains of new-born care where students lack confidence.

3) Determine factors associated with student's confidence in the domain of new-born care.

4) Assess the relationships between teaching methods, clinical mentoring/supervision and confidence in the domain of new-born care.

\subsection{Variables}

\subsubsection{Dependent Variable}

Confidence in new born care.

\subsubsection{Independent Variables}

Socio demographic Variables

Teaching methods

Time to practice clinical skills prior to contact with women,

Supervision/mentorship during clinical practice

Availability of teaching and learning aids

\section{Literature Review}

\subsection{Literature Review}

It is worthwhile to invest in midwives irrespective of the available financial and other resources within countries. Evidence derived from randomized controlled trials in high-income settings [13], and from practical experience in low-income, middle-income settings such as Sri Lanka, and high-income countries such as Sweden [14], show that skilled professional care contributes to high quality maternal and newborn care. Midwives contribute to saving lives, preventing physi- 
cal and psychological morbidities and lessening the social and economic burden on families, irrespective of socio-economic settings. Midwives also prevent unnecessary interventions such as episiotomies and caesarean births [15].

A Midwife as defined by the International Confederation of Midwives [16] is a responsible and accountable professional who works in partnership with women to give the necessary support, care and advice during pregnancy, labour and the postpartum period. The midwife differs from other professionals with midwifery skills in their philosophy of "women centered care" and "maintaining normalcy of birth" for best outcomes [16]. Birth is viewed as a natural process that has a profound meaning to individuals and the society. The possibility of complications is not allowed to preempt all other values associated with the woman's experience of bearing and giving birth to a child [17]. The midwifery model establishes the pregnant woman as an active partner in her own care and recognizes her as the primary actor and decision-maker [17].

Midwives, though recognized as primary providers of childbirth services [4] [18] can only deliver quality maternal and child health services if they are educated, trained to proficiency, regulated and supported by the health system. For midwives to practice the full scope of midwifery practice as defined by ICM, good quality basic education and regulation are pre-requisites.

The ICM emphasizes on midwife's competencies-the core essential skills to be licensed as a midwife [19], and recommends 18 months of additional education in midwifery after nursing to qualify as a midwife, and at least 3 years for direct entry candidates [18] [19].

Midwifery education and scope of practice of midwives greatly varies across the world. For instance, most of the countries in Europe fulfill the ICM recommended duration of midwifery education, and many have direct entry programs. Yet the European countries also vary in the quality of education, regulatory frameworks, and scope of practice for midwives. The European Union is in the process of standardizing nursing and midwifery education in the 33 member countries that cover almost the entire Europe [20].

A survey by UNFPA and ICM, in low and middle income countries showed differences in midwifery pathways and basic education [21]. There were three pathways to midwifery in the 58 countries that were surveyed; $70 \%$ of the countries followed the direct entry pathway, $45 \%$ had nursing and an additional period of post nursing midwifery education, and $43 \%$ had combined programmes for nursing and midwifery education [21]. The duration of midwifery education programmes ranged from 6 months to 5 years. Though many countries have a government designated regulatory body which provides a license and protects the title of midwife, only in three countries, it was distinct from nursing.

The UNFPA survey further showed $43 \%$ shortage of Skilled Birth Attendants (SBAs) in 38 countries [21]. In the process of rapid scaling up of SBAs, many low-income and middle-income countries have taken shortcuts and detours, compromising on quality to achieve quantity [22]. Several cadres differing in 
length of education, competences, and role, have been included as SBAs [24].

The SBAs lack the competence to provide comprehensive services [23], and the regulatory frameworks for SBAs are weak [24]. In the low-income and middle-income countries where the context is high mortality, adequately educated and trained midwives are needed the most.

Low and middle income countries account for $99 \%(284,000)$ of the global maternal deaths, the majority of which are in sub-Saharan Africa $(162,000)$ and southern Asia $(83,000)$. These two regions accounted for $85 \%$ of the global burden, with sub-Saharan Africa alone accounting for 56\%. The MMR in low resource regions was 15 times higher than in resource rich regions [25].

Each year, about four million newborns die before they are four weeks old; $98 \%$ of these deaths occur in low and middle income countries. Newborn deaths now contribute to about $40 \%$ of all deaths in children under five years of age globally and more than half of the infant mortality. Rates are highest in sub-Saharan Africa and Asia. Two thirds of newborn deaths occur in the WHO Regions of Africa (28\%) and South-East Asia (36\%).

Given this high mortality and the lack of standardization in midwifery education, and regulation it is important to assess how successful are the various midwifery programmes in preparing confident midwives, in a variety of settings across countries. Most of the respondents (54.6\%) indicated that they had enough time to practice on models in the labs before handling actual patients. However, the number of respondents who indicated that they did not have enough time to practice on models is too high (45.4\%). this is not good enough as practice in the labs makes students more confident when they practice on mothers.

\subsection{Conclusion}

Adequate theoretical and clinical midwifery education is required to produce confident midwives who will be able to provide quality care to newborns and enhance newborn survival. Zambia has increased the number of Midwifery training institutions in order to increase the number of Midwives in the country. This study was important in finding out how competent midwifery students were at completion of their training as it would provide a guide as to whether they would be able to practice with competence as qualified midwives.

\section{Methodology}

\subsection{Study Design}

The first phase consisted of a quick situation analysis of midwifery education and regulation in Zambia, followed by a cross-sectional survey through a self-administered questionnaire to assess the confidence of final year midwifery students.

\subsection{Study Setting}

The study was conducted at Midwifery Schools from Lusaka, Kabwe, Copper- 
belt, southern and Mchinga provinces of Zambia. The study setting is further displayed in Table 4 below.

\subsection{Study Population}

The study population comprised all midwifery students remaining with two weeks before completing their training program, and would have completed their curriculum and waiting for their final examinations in the selected midwifery schools in Zambia in November, 2016.

\subsection{Sample Selection}

Guided by the situation analysis, midwifery educational institutions were randomly selected from selected institution in each province. All students who were ready to sit for their final examinations were included in the study. The institutions were selected as follows:

Schools were stratified according to the midwifery training program which they offer, that is, certified midwifery, certificate in midwifery and diploma in nursing and midwifery. Then Simple random sampling method was used for selecting participating schools from two strata (certified midwifery and certificate in midwifery). Simple random sampling was also used to select the participants who met the inclusion criteria. This was be done by writing "yes" or "no" on equal number of pieces of paper, and the students who picked the papers with "yes" were included in the study. Convenience sampling method was used to select the two schools from the third strata (diploma in nursing and midwifery).

\subsubsection{Inclusion Criteria}

1) All midwifery schools that offer registered midwifery certificate, registered nurse midwifery diploma or direct entry midwifery certificate will be included in

Table 4. Study setting.

\begin{tabular}{|c|c|c|c|}
\hline SN & School & Location & Qualification Offered \\
\hline 1. & Kitwe School of Midwifery & Copperbelt province, Zambia & $\begin{array}{l}\text { Certificate in midwifery to } \\
\text { diploma in nursing holders }\end{array}$ \\
\hline 2. & Lusaka School of Midwifery & Lusaka Province, Zambia & $\begin{array}{l}\text { Certificate in midwifery to } \\
\text { diploma in nursing holders }\end{array}$ \\
\hline 3. & Chilonga School of Midwifery & Mchinga Province of Zambia & $\begin{array}{l}\text { Certificate in midwifery to } \\
\text { diploma in nursing holders }\end{array}$ \\
\hline 4. & Kabwe School of Midwifery & Central Province of Zambia & $\begin{array}{l}\text { Certificate in midwifery to } \\
\text { diploma in nursing holders }\end{array}$ \\
\hline 5. & $\begin{array}{c}\text { Lusaka School of } \\
\text { Nursing and Midwifery }\end{array}$ & Lusaka Province, Zambia & $\begin{array}{c}\text { Registered Nurse Midwife } \\
\text { certificate (to school leavers) }\end{array}$ \\
\hline 6. & $\begin{array}{c}\text { Monze School of } \\
\text { Nursing and Midwifery }\end{array}$ & Southern Province, Zambia & $\begin{array}{c}\text { Registered nurse midwife } \\
\text { certificate (to school leavers) }\end{array}$ \\
\hline 7. & Roan School of Midwifery & Copperbelt province, Zambia & $\begin{array}{l}\text { Certificate in midwifery } \\
\text { (to school leavers) }\end{array}$ \\
\hline 8. & Nchanga School of Midwifery & Copperbelt Province, Zambia & $\begin{array}{l}\text { Certificate in midwifery } \\
\text { (to school leavers) }\end{array}$ \\
\hline
\end{tabular}


the study.

2) All midwifery students at the end of their training, two weeks before they sat for their final examinations were included in the study.

3) All midwifery students who consented to participate.

4) All midwifery students who met the inclusion criteria.

\subsubsection{Exclusion Criteria}

1) All midwifery schools that offer enrolled midwifery certificate were excluded from taking part in the study.

2) All midwifery students who were deferred from writing the examination.

3) All midwifery students who did not consent to take part in the study.

\subsection{Sample Size}

Since we do not know the proportions of the confidence of midwifery students in midwifery competences, we used 50\% [26]. Thus $\mathrm{p}=50 \%=0.5$

$$
\begin{gathered}
n=\frac{z^{2} p(1-p)}{d^{2}} \\
n=\frac{1.96^{2} \times 0.5 \times 0.5}{0.05^{2}}=384
\end{gathered}
$$

Adjustment for population size was done using the following formula

$$
\begin{gathered}
n=n / 1+n / N \\
n=384 / 1+384 / 459=209
\end{gathered}
$$

These were distributed proportionally among the selected schools as follows;

Lusaka School of midwifery

Lusaka School of nursing and midwifery

Kitwe School of midwifery

Kabwe School of midwifery

Chilonga School of midwifery

Monze School of nursing and midwifery

Roan School of midwifery (DEM)

Nchanga School of midwifery (DEM)

Lusaka School of Nursing and Midwifery, Chilonga, and Kabwe wrote the exam as we waited for Ethical approval, so the 71 students who should have been interviewed from these schools were shared among the 5 remaining schools by dividing 71 by 5 , giving each school an extra 14 students and 15 students to Monze School of Nursing and Midwifery as follows; Lusaka School of Midwifery $=33$, Kitwe School of Midwifery $=51$, Monze School of Nursing and Midwifery $=46$, Roan School of Midwifery $(\mathrm{DEM}),=41$, Nchanga School of Midwifery $(\mathrm{DEM})=41$

\subsection{Data Collection Tool}

\subsubsection{Questionnaire}

The study used a self-administered questionnaire called Pre-Service Education 
Assessment Tool developed by ICM in 2010, amended in 2013 [19]. A questionnaire was designed by adapting the list of skill statements from the four selected domains of ICM competencies. The questionnaire has four competency domains from the seven listed by ICM. Only the basic or core skills for each of the four domains have been included in the questionnaire. Modifications were made to the tool so that it suits the Zambian midwifery education. The process of modification included the review of the questionnaire by country teams in terms of questions related to background characteristics of students, their clinical exposure and relevance of skill statements under the 4 selected domains.

The questionnaire includes background characteristics of students and four competence domains which are; antenatal procedure/skill, preparedness and complication readiness, postnatal care and new-born care. The students were assessed for confidence levels in each skill statement on a four point scale; one (1) representing not confident and four (4) representing one being confident.

\subsubsection{Check List}

The study also used a check list to obtain information on the teaching-learning environment of participating institutions. This check list sought to obtain details such as the type of institution (i.e. Private/public, direct entry/other), its location (urban/rural), total number of midwifery students, facilities such as skill laboratories, practice equipment, library, and number of midwifery teachers, their qualification, training for teaching and continuing education.

\subsection{Pilot Study}

A Pilot study was conducted at Ndola School of Midwifery. This school has similar characteristics with other midwifery training schools and was easily accessed by the investigators. The school is situated in the Copperbelt Province of Zambia.

The purpose of the pre-test was to identify any part of the instrument that was difficult to understand or misinterpreted by the respondent, determine clarity of the instrument, determine whether the sequencing of questions was effective, determine acceptability of questions and willingness to respond or answer questions, detected any errors in the questionnaire for the main study and assessed the appropriateness and clarity of questions.

\subsection{Data Collection Technique}

In this study, a pre-tested questionnaire, with closed ended questions was used as it allows quick recording of responses and saves on time [27], and because participants learn in English as the language of instruction. The actual dates for data collection (two weeks before final examinations) were obtained from General Nursing Council of Zambia by the researchers. After obtaining this information the cohort of final-year students was contacted and permission to conduct the research study was sought. The students who consented were provided with the questionnaire in the classroom and asked to fill it in. The researcher/s were present during that period. The Principal investigator and co-investigators 
trained teams from each province for data collection, data entry and management.

Data quality checks were done immediately after the interview to ensure that the data was correct and omissions were filled in. A standard common structure was used for entering the survey data which could be adapted to country needs. The SPSS was used to enter and analyse data and the core team ensured appropriate data entry and cleaning.

\subsection{Ethical Consideration}

The proposed study included personal information from students and the participating educational institutions therefore the researchers took caution and treated the data as confidential. Permission was sought from UNZABREC and from General Nursing Council, Midwifery Schools and Medical superintendents where the schools are situated including Nursing managers and Principal Tutors.

Written consent was obtained from each participant before the interview after explaining to the participant the information that needed to be collected. The researchers also assured the participants of confidentiality and anonymity and that no name or any form of identity would be indicated on the interview schedule form. Complete confidentiality of the respondents and of the participating educational institutions was ensured by assigning codes during handling data and data entry and analysis. No one, except the Principal investigator had access to the codes.

Names of participants were not indicated on the questionnaire; however, the questionnaires had serial numbers for the purpose of data entry. The participants filled in the questionnaire with each of them sited at their own desk. The researchers ensured that each interview lasted about 20 to 50 minutes and not longer than that period of time to prevent fatigue. The participants were assured that they had a right to access to the examination and that they would still be allowed to attended their final examination.

To prevent halo effect, researchers from University recruited research assistants from the study setting for data collection. The participants were informed that participation in the study was purely on voluntary basis.

\section{Data Presentation and Analysis}

\subsection{Data Analysis}

Following data collection, the pre-coded questionnaires were double checked for completeness, consistency, legibility and accuracy. Numerical codes were used for coding. The flaws on the questionnaires were corrected.

Factor analysis using Principal Component Analysis was carried out to reduce the number of skills statements into subscales for each of the four selected domains of antepartum, intrapartum, newborn and postpartum care. The scores on confidence for the identified subscales were used to study associations of confidence and other variables. Epidemiological methods were used to carry out the analysis. 
The Statistical Package for Social Sciences (SPSS) was used to enter and analyze data. The scores on confidence for new born care were analyzed against the ICM competencies using SPSS. Epidemiological methods were used to study associations between confidence and background variables, and variables related to teaching-learning methods.

\subsection{Presentation of Findings}

Data were presented using tables. Demographic characteristics were presented in frequency tables. Age, duration of the programme they are enrolled, number of annual births which take place in the hospital/s/health centers and number of births they attended to during their entire education period have been presented as means.

Sex, highest qualification at the time of admission to this programme, they were enrolled in, which type of health facility they went to for clinical practice and whether midwifery was their first choice of profession have been presented as frequencies. These frequencies depicted proportions of each category of the respective variable.

The variables for new-born care included; What teaching method was used for their classroom session, whether they had enough time to practice clinical skills prior to contact with women, whether they were confident when they practiced for the first time on newborns, how satisfied they were with the supervision/mentoring during clinical practice and how confident they were to perform this skill independently.

Majority of the respondents (51.8\%) were aged between 18 to 28 years and most of them (87.6\%) were female. Those who were aged 40 to 50 years represented $9.8 \%$. At admission to training, most (60.8\%) of the students had a Grade 12 certificate as their highest educational qualification, $37.8 \%$ had a diploma in nursing while $0.5 \%$ was a Community Health Assistant. Most (48.5\%) of the respondents were enrolled for a certificate in Midwifery, while 38.1\% were Registered nurses who were training to obtain a certificate in Midwifery, and $13.4 \%$ were enrolled as Registered Nurse Midwifery student. The duration of their programs were 1 year for Registered Nurses/Registered Midwives which represented 39.2\% of the respondents, 2 years for Certificate in Midwifery program which was $47.9 \%$ of the respondents and 3.5 years for the Registered Nurse Midwifery program which represented $12.9 \%$ of the respondents. Majority of the respondents 86.6\%) would obtain a certificate at completion of their training, while $13.4 \%$ would obtain a Diploma. Majority of the respondents (35\%) were practicing at Level 1, 2 and Level 3 hospitals and also clinics for their clinical placement. Only $0.5 \%$ practiced at Level 1 and 3 hospitals. Majority of the practicum areas (96.7\%) had 100 to 10,000 annual births and only one facility had 50,000 annual births and above. Most of the respondents (63.4\%) attended to more than 30 births during their training period, while $5.2 \%$ attended to exactly 30 births during their training period. The first choice for their profession was Midwifery for 
$78.4 \%$ of the respondents while $21.6 \%$ respondents had other first choices for a profession. Majority of the respondents (51.8\%) had given birth already before coming for Midwifery training.

Most $(38.1 \%)$ of the respondents mentioned Lecture and Demonstration as the method of teaching that was used to impart knowledge in procedures/skills in New-born care, while $37.1 \%$ said they were taught by Lecture and Roleplay. Teaching by Lecture, roleplay, Demonstration, Self-directed learning and presentations by students represented $22.2 \%$ of the study sample. The majority of respondents $(54.6 \%)$ responded that they had enough time to practice on models in the Laboratories before going to the actual clinical areas, and half of the respondents $(50 \%)$ said they were confident when they practiced the first time on newborns while the other half (50\%) said they were not at all confident. Majority of the respondents (77.3\%) said they were satisfied with their Clinical supervision, and $95.9 \%$ of them were confident to perform the skills independently.

\section{Discussion of Findings}

\subsection{Characteristics of the Sample}

Most of the respondents were aged between 18 and 28 years, followed by those who were aged 29 to 39 years (38.3\%), and only $9.8 \%$ of the respondents were aged 40 to 50 years, as shown in Table 5. This could be attributed to the age when most people complete their secondary school education and move on to college. Most people complete secondary education at the age of 18 years according to the Zambian education policy where pupils start Grade 1 at the age of 7 years and would therefore complete Grade 12 at 18 years of age and proceed to college. This is similar to findings by Yigzaw et al. in 2015 [28] who also found that the mean age for their study participants was 21.7 years. Other respondents were aged 29 to 39 years (38.3\%) and this could encompass mostly the students who were studying for a certificate in Midwifery after obtaining their Diploma in Nursing. According to Ministry of Health regulations, Zambia, nurses have to work at least 2 years after completing a training before moving on to another training. The fact that most $(51.8 \%)$ of the students had given birth before (Table 5) could also imply that some of the students got married and started raising their families after completing their Diploma in nursing studies, hence waiting for some time before applying for the Certificate in Midwifery.

The highest qualification at admission for most $(60.8 \%)$ of the respondents was a Grade 12 certificate, and this is because most of the respondents were coming from secondary school and pursuing a Certificate in Midwifery or a Diploma in Registered Nursing and Midwifery (Table 5). A number (38.7\%) of them were Registered nurses pursuing an added qualification of a certificate in Midwifery. The program duration was one (1) year for $39.2 \%$ of the respondents and these were the Registered nurses who were studying to obtain a certificate in Midwifery, followed by $47.9 \%$ who were studying for a certificate in Midwifery, and theses comprised school leavers. The other respondents (12.9\%) would 
Table 5. Demographic characteristics of the Midwifery students $(\mathrm{N}=194)$.

\begin{tabular}{|c|c|c|}
\hline \multicolumn{3}{|c|}{ Demographic characteristics of the midwifery students } \\
\hline Characteristic & Frequency & Per cent \\
\hline \multicolumn{3}{|l|}{ Age } \\
\hline $18-28$ Years & 100 & 51.8 \\
\hline 29 - 39 Years & 74 & 38.3 \\
\hline $40-50$ Years & 19 & 9.8 \\
\hline \multicolumn{3}{|l|}{$\operatorname{Sex}(N=193)$} \\
\hline Male & 24 & 12.4 \\
\hline Female & 169 & 87.6 \\
\hline \multicolumn{3}{|l|}{ Highest qualification at admission } \\
\hline Grade 12 certificate & 118 & 60.8 \\
\hline $\mathrm{CHA}$ & 1 & 0.5 \\
\hline Registered Nurse Diploma & 75 & 38.7 \\
\hline \multicolumn{3}{|l|}{ Type of program enrolled in } \\
\hline Certificate midwifery & 94 & 48.5 \\
\hline Registered Nursing/Registered Midwifery & 74 & 38.1 \\
\hline Registered Nurse Midwifery & 26 & 13.4 \\
\hline \multicolumn{3}{|l|}{ Duration of program enrolled in } \\
\hline 1 Year & 76 & 39.2 \\
\hline 2 Years & 93 & 47.9 \\
\hline 3.5 Years & 25 & 12.9 \\
\hline \multicolumn{3}{|l|}{ Level of the program } \\
\hline Certificate & 168 & 86.6 \\
\hline Diploma & 26 & 13.4 \\
\hline \multicolumn{3}{|c|}{ Type of health facility for clinical practice $(\mathrm{N}=183)$} \\
\hline Level 1 hospital & 5 & 2.7 \\
\hline Level 2 hospital & 6 & 3.3 \\
\hline Level 3 hospital & 31 & 16.9 \\
\hline Clinic & 3 & 1.6 \\
\hline Level 1 and 2 hospital & 9 & 4.9 \\
\hline Level 1 and 3 hospital & 1 & 0.5 \\
\hline Level 1 and 2 hospital and clinic & 13 & 7.1 \\
\hline Level 1 and 3 hospital and clinic & 4 & 2.2 \\
\hline Level 2 and 3 hospital & 9 & 4.9 \\
\hline Level 1, 2 and 3 hospital and clinic & 64 & 35.0 \\
\hline Level 1 hospital and clinic & 3 & 1.6 \\
\hline Level 2 hospital and clinic & 2 & 1.1 \\
\hline
\end{tabular}


Continued

\begin{tabular}{|c|c|c|}
\hline 14 & 27 & 14.8 \\
\hline 15 & 6 & 3.3 \\
\hline \multicolumn{3}{|c|}{ Number of annual births in the hospital of training $(\mathrm{N}=184)$} \\
\hline $100-10,000$ & 178 & 96.7 \\
\hline $10,001-20,000$ & 2 & 1.1 \\
\hline $20,001-30,000$ & 2 & 1.1 \\
\hline $30,001-40,000$ & 0 & 0.0 \\
\hline $40,001-50,000$ & 1 & 0.5 \\
\hline 50,001 and above & 1 & 0.5 \\
\hline \multicolumn{3}{|c|}{ Number of births attended to during entire training } \\
\hline$<30$ & 61 & 31.4 \\
\hline 30 & 10 & 5.2 \\
\hline$>30$ & 123 & 63.4 \\
\hline \multicolumn{3}{|c|}{ Midwifery first choice of profession } \\
\hline No & 42 & 21.6 \\
\hline Yes & 152 & 78.4 \\
\hline \multicolumn{3}{|c|}{ Have you given birth before? $(\mathrm{N}=193)$} \\
\hline No & 60 & 31.1 \\
\hline Yes & 100 & 51.8 \\
\hline N/A & 33 & 17.1 \\
\hline
\end{tabular}

complete their training in 3 and half years and obtain a Diploma in Registered Nursing and Midwifery (Table 5). This program was introduced in 2012 in just two (2) Nursing schools in Zambia to respond to shortages of staff and skilled manpower to attend to reproductive Health issues especially in rural areas. The level of the program was a certificate for $86.8 \%$ of the respondents, which comprised of the school leavers who were studying for a certificate in Midwifery and would be enrolled by the Nursing Council as Certified Midwives, and also the Registered Nurses who were pursuing a certificate in Midwifery. The level of Diploma qualification was $13.4 \%$ and these were also school leavers who were studying for a Diploma in Registered Nursing and Midwifery as shown in Table 5. Zambia introduced the Registered Nursing and Midwifery program in 2012 in an effort to equip nurses with Midwifery skills and be able to provide skilled care for clients seeking Reproductive Health services as most nurses would be sent to work in remote areas after completion of their training. With a Midwifery training, they would be better able to man a centre and provide all clients with basic care and also Midwifery care to clients needing them.

Majority of the respondents were placed in Levels 1, 2 and 3 Hospitals and also clinics for their clinical practice, with between one hundred to ten thousand annual births, followed by $16.9 \%$ who were placed in Level 3 hospitals only 
(Table 5). The clinical placement for the students matters in their attainment of skills because each level of care has their scope of practice, like at a clinic, mostly clients needing specialized care would quickly be referred to a bigger centre for management so students placed in this facility would learn the principles of prompt referral for further management of clients. It is important therefore to place students in various Levels of health care facilities during the course of their training to equip them with skills of managing clients at all levels of health care. Concerning the number of births attended to during training, most (63.4\%) of the respondents had attended to more than 30 births during the course of their training. This ensures that by the time the students graduate, they have basic knowledge and skills in attending to real clients and not only practicing in Labs. This makes them attain a level of confidence in attending to clients even after completion of their training. However, $31.4 \%$ of the respondents only attended to less than 30 births during their period of training. As shown in Table 5. This may lead to inadequacy in confidence in performing newborn skills after completion of training as the students would not have had enough guidance on attending to clients during their training. This is similar to findings by Yigzaw et al. in 2015 [28] who assessed competence of midwifery students at the point of graduation in Ethiopia and found that only $32 \%$ of the respondents managed 20 or more births during their entire training. This impacts negatively on the students as they will not be confident in performing the skills due to inadequate exposure during their training. Majority of the respondents (78.4\%) had midwifery as their first choice of profession when they went into training as shown in Table 5. It is important that individuals train in the field of their choice to enhance good practice after graduation, unlike when they are coerced into a profession they are not interested in. This can lead to failure in performance as the individual will not have the interest to work and this would translate into negative attitude and poor patient care. Estimated number of births attended to during the entire training was significantly associated with confidence to perform new born care skills independently (p value 0.025 \} as shown in Table 7 .

\subsection{Factors Associated with Students' Confidence in Newborn Care}

\subsubsection{Teaching Methods}

On acquiring the Midwifery skills, most students (38.1\%) responded that a combination of Lecture and Demonstration was used for classroom sessions as shown in Table 6. This is an effective way of teaching students as they first learn about the skills and acquire theoretical knowledge, and later procedures are demonstrated to them to show them how the procedures are done. A number of the respondents mentioned Lecture and Role play as the methods used to teach them the procedures and skills in new born care (Table 6). Like Lecture and Demonstration, this is another effective way of teaching skills to students as they are not only taught in the classroom, but are also allowed to see/do the procedures/skills being performed and are therefore able to remember them. Katowa-Mukwato et al. in 
Table 6. Newborn care procedures/skills of the Midwifery students $(\mathrm{N}=194)$.

\begin{tabular}{lcc}
\hline Newborn care procedures/skills of the midwifery students & & \\
\hline Characteristic & Frequency & Percent \\
Teaching method used for classroom session & 72 & 37.1 \\
Lecture and role play & 75 & 38.1 \\
Lecture and demonstration & 4 & 2.1 \\
Group work, online, self-directed and presentation by students & 43 & 22.2 \\
$\begin{array}{l}\text { Lecture, role play, demonstration, self-directed learning, } \\
\text { and presentation by students }\end{array}$ & 88 & 45.4 \\
Did you have enough time to practice on models in the labs? & 106 & 54.6 \\
No & & \\
Yes & 97 & 50.0 \\
Confidence when practiced for the first time on the newborns & 97 & 50.0 \\
Not confident & & \\
Confident & 48 & 22.7 \\
Satisfaction with the supervision during clinical practice & 150 & 77.3 \\
Not satisfied & & 9.1 \\
Satisfied & & \\
Confidence to perform skills independently & & \\
Not confident & & \\
Confident & & \\
\hline
\end{tabular}

2017 [29] also found that $35.5 \%$ of learners were kinaesthetic and would learn best by doing the procedure. However, only $2.1 \%$ of the respondents mentioned group work, online, online learning, self-directed learning and presentations by other students as teaching methods that were used during classroom sessions (Table 6). Most of the respondents (54.6\%) responded that they had enough time to practice on models in the Lab before handling real clients. This helps to build some confidence in the students and helps them to practice with some confidence when they have to handle real clients. This also protects patients from some harmful practices which may be done by students, especially if coupled with lack of/inadequate clinical supervision [30].

Most of the respondents (54.6\%) indicated that they had enough time to practice on models in the labs before handling actual patients. However, according to Table 6, the number of respondents who indicated that they did not have enough time to practice on models is too high (45.4\%). this is not good enough as practice in the labs makes students more confident when they practice on mothers and newborns. A study conducted by Lendahls in 2017 also concluded that simulation and skills training in the skills labs supported the development of Midwifery skills [31]. Inadequate practice in the labs may be attributed by less time allocated to it or too few mannequins for all students to practice.

There was no difference in respondent's confidence when practicing the procedures for the first time on newborns. Respondents who felt confident practicing on 
mothers for the first time were $50 \%$, and so were those not confident, as shown in Table 6. The lack of confidence in some of the students may be attributed to not having enough time to practice on models before handling mothers and newborns.

\subsubsection{Supervision during Clinical Practice}

Regarding their satisfaction with clinical supervision during their practice, $22.7 \%$ responded that they were not satisfied while $77.3 \%$ responded that they were satisfied, as shown in Table 6. For students to be confident in clinical procedures, mentorship and supervision has to be adequate so that students are adequately guided in their clinical procedures [30]. However, in spite of some respondents saying that they had inadequate time to practice in the labs, and some saying that supervision was inadequate, most (95.9\%) responded that they felt confident to perform the skills independently as shown in Table 6. This confidence may have developed after performing the procedures several times.

\subsection{Relationships between Variables}

Cross-tabulation between confidence to perform new-born skills independently and demographic characteristics revealed no significant association (Table 7). However, cross tabulation between confidence to perform skills independently by other new-born care procedures/skills revealed significant associations as shown in Table 8 . There was significant association between confidence to perform skills independently and having enough time to practice on models in the labs $(\mathrm{p}$ value $=0.024)$, confidence when practiced for the first time on newborns ( $\mathrm{p}$ value $=0.007)$ and satisfaction with supervision during clinical practice ( $\mathrm{p}$ value $=0.000)($ Table 8$)$. Binary logistic regression of characteristics associated with confidence to perform new-born skills independently revealed significant association between satisfaction with clinical supervision and confidence to perform skills independently (CI 5.31, p value 0.007) as shown in Table 9.

\subsection{Limitations of the Study}

The study only picked some of the Midwifery schools and not all so the results are not representative of all the midwifery students in the country.

\subsection{Dissemination and Utilization of Findings}

The information will be disseminated at the Principal Tutors' meetings, ECSACON, national and regional meetings, National Health Research Conferences in Zambia and other provincial meetings. Further, a copy of the abstract will be sent to the General Nursing council of Zambia so that the findings of the study are incorporated when reviewing the Midwifery curricular. A copy of the abstract will also be sent to the Ministry of Health Headquarters.

\subsection{Conclusions and Recommendations}

\subsubsection{Conclusion}

Midwifery students need quality training both theoretically and practically in 
Table 7. Confidence to perform skills independently by demographic characteristics of the Midwifery students $(\mathrm{N}=194)$.

\begin{tabular}{|c|c|c|c|}
\hline \multicolumn{4}{|c|}{ Confidence to perform skills independently by demographic characteristics of the midwifery students } \\
\hline \multirow{2}{*}{ Characteristic } & \multicolumn{2}{|c|}{ Confidence to perform skills independently } & \multirow{2}{*}{ P-value } \\
\hline & Not confident $\mathbf{N}(\%)$ & Confident N (\%) & \\
\hline \multicolumn{4}{|l|}{ Age } \\
\hline $18-28$ Years & $5(5.0)$ & $95(95.0)$ & 0.146 \\
\hline 29 - 39 Years & $1(1.4)$ & $73(98.6)$ & \\
\hline 40 - 50 Years & $2(10.5)$ & $17(89.5)$ & \\
\hline \multicolumn{4}{|l|}{ Gender } \\
\hline Male & $2(8.3)$ & $22(91.7)$ & a 0.261 \\
\hline Female & $6(3.6)$ & $163(94.6)$ & \\
\hline \multicolumn{4}{|l|}{ Highest qualification at time of admission } \\
\hline Community Health Assistant & $0(0.0)$ & $1(100.0)$ & 0.975 \\
\hline Grade twelve & $5(4.2)$ & $113(95.8)$ & \\
\hline Registered Nurse & $3(4.0)$ & $72(96.0)$ & \\
\hline \multicolumn{4}{|l|}{ Type of programme enrolled in } \\
\hline Certified Midwifery & $4(4.3)$ & $90(95.7)$ & 0.995 \\
\hline Registered Nurse/Registered Midwifery & $3(4.1)$ & $71(95.9)$ & \\
\hline Registered Nurse Midwife & $1(3.8)$ & $25(96.2)$ & \\
\hline \multicolumn{4}{|l|}{ Duration of programme enrolled in } \\
\hline 1 Year & $4(5.3)$ & $72(94.7)$ & 0.802 \\
\hline 2 Years & $3(3.2)$ & $90(96.8)$ & \\
\hline 3.5 Years & $1(4.0)$ & $24(96.0)$ & \\
\hline \multicolumn{4}{|l|}{ Qualification of the programme enrolled in } \\
\hline Certificate & $7(4.2)$ & $161(95.8)$ & 1.000 \\
\hline Diploma & $1(3.8)$ & $25(96.2)$ & \\
\hline \multicolumn{4}{|l|}{ Types of health facilities for clinical practice } \\
\hline Level 1 hospital & $1(20.0)$ & $4(80.0)$ & 0.142 \\
\hline Level 2 hospital & $0(0.0)$ & $6(100.0)$ & \\
\hline Level 3 hospital & $0(0.0)$ & $31(100.0)$ & \\
\hline Clinic & $1(33.3)$ & $2(66.7)$ & \\
\hline Level 1 and 2 hospitals & $1(11.1)$ & $8(88.9)$ & \\
\hline Level 1 and 3 hospitals & $0(0.0)$ & $1(100.0)$ & \\
\hline Level 1, 2 hospitals and clinic & $1(7.7)$ & $12(92.3)$ & \\
\hline Level 1, 3 hospitals and clinic & $1(25.0)$ & $3(75.0)$ & \\
\hline Level 2 and 3 hospital and clinic & $0(0.0)$ & $9(100.0)$ & \\
\hline Level 1, 2, 3 and clinic & $1(1.6)$ & $63(98.4)$ & \\
\hline Level 1 hospital and clinic & $0(0.0)$ & $3(100.0)$ & \\
\hline
\end{tabular}




\section{Continued}

Level 2 and other

Level 2 hospital and clinic

Level 3 hospital and clinic
$0(0.0)$

$1(3.7)$

$0(0.0)$

$6(9.8)$

$0(0.0)$

$2(1.6)$

more than 30

Was midwifery your first choice of profession?

No

Yes

Have you ever given birth?

No

Yes

Not applicable

Number of births that take place annually in the hospital of training $[\mathrm{N}$; Mean $(\mathrm{SD})](\mathrm{N}=184)$

$2(4.8)$

$6(3.9)$

$4(4.0)$

$21(6.1)$

$$
2(100.0)
$$

$6(100.0)$

55 (90.2)

0.025

$10(100.0)$

$121(98.4)$

40 (95.2)

${ }^{\mathrm{a}} 0.684$

$146(96.1)$

$58(96.7)$

0.815

$96(96.0)$

$31(93.9)$

$8 ; 1173.75(308.59) \quad 176 ; 8231.15(7534.31)$

0.792

There was a significant relationship between estimated number of births attended to during entire training and confidence to perform skills independently with a p value of 0.025 .

Table 8. Confidence to perform skills independently by other Newborn care procedures/skills $(\mathrm{N}=194)$.

\begin{tabular}{|c|c|c|c|}
\hline \multicolumn{4}{|c|}{ Confidence to perform skills independently by other newborn care procedures/skills } \\
\hline \multirow{2}{*}{ Characteristic } & \multicolumn{2}{|c|}{ Confidence to perform skills independently } & \multirow{2}{*}{ P-value* } \\
\hline & Not confident $\mathrm{N}(\%)$ & Confident N (\%) & \\
\hline \multicolumn{4}{|l|}{ Teaching methods used for classroom session } \\
\hline Lecture and role play & $1(1.4)$ & $71(98.6)$ & 0.079 \\
\hline Lecture and demonstration & $3(4.0)$ & $72(96.0)$ & \\
\hline Group work, online, self-directed and presentation by students & $1(25.0)$ & $3(75.0)$ & \\
\hline Lecture, role play, demonstration, self-directed learning, and presentation by students & $3(7.0)$ & $40(93.0)$ & \\
\hline \multicolumn{4}{|l|}{ Did you have enough time to practice on models in the labs? } \\
\hline No & $7(8.0)$ & $81(92.0)$ & a 0.024 \\
\hline Yes & $1(0.9)$ & $105(99.1)$ & \\
\hline \multicolumn{4}{|l|}{ Confidence when practiced for the first time on newborns } \\
\hline Not confident & $8(8.2)$ & $89(91.8)$ & ${ }^{\mathrm{a}} 0.007$ \\
\hline Confident & $0(0.0)$ & $97(100.0)$ & \\
\hline \multicolumn{4}{|l|}{ Satisfaction with supervision during clinical practice } \\
\hline Not satisfied & $7(15.9)$ & $37(84.1)$ & a 0.000 \\
\hline Satisfied & $1(0.7)$ & $149(99.3)$ & \\
\hline
\end{tabular}

There was no relationship between teaching methods and confidence to perform skills independently ( $\mathrm{p}$ value 0.097 ) while having enough time to practice on models in the labs was significantly associated with confidence to perform skills independently ( $\mathrm{p}$ value 0.024 ), confidence when practiced for the first time on mothers was significantly associated with confidence to perform skills independently ( $p$ value 0.007 ), and so was satisfaction with supervision during clinical practice ( $\mathrm{p}$ value 0.000 ). 
Table 9. Binary logistic regression model of characteristics associated with confidence to perform Newborn skills independently $(\mathrm{N}=194)$.

\begin{tabular}{|c|c|c|c|c|}
\hline \multicolumn{5}{|c|}{ Binary logistic regression model of characteristics associated with confidence to perform newborn skills independently } \\
\hline \multirow{2}{*}{ Characteristic } & \multicolumn{2}{|c|}{$\begin{array}{l}\text { Confidence to perform } \\
\text { skills independently }\end{array}$} & \multirow{2}{*}{ UAOR (95\% CI; p-value) } & \multirow{2}{*}{ AOR (95\% CI; p-value) } \\
\hline & $\begin{array}{l}\text { Not confident } \\
\text { N (\%) }\end{array}$ & $\begin{array}{l}\text { Confident } \\
\mathrm{N}(\%)\end{array}$ & & \\
\hline \multicolumn{5}{|c|}{ Had enough time to practice on models in the labs } \\
\hline No & $7(8.0)$ & $81(92.0)$ & $\operatorname{Ref}(1.0)$ & $\operatorname{Ref}(1.0)$ \\
\hline Yes & $1(0.9)$ & $105(99.1)$ & $9.07(1.09-75.24 ; 0.041)$ & $3.63(0.39-33.26 ; 0.255)$ \\
\hline \multicolumn{5}{|c|}{ Confidence when practiced for the first time on newborn } \\
\hline Not confident & $8(8.2)$ & $89(91.8)$ & $\operatorname{Ref}(1.0)$ & $\operatorname{Ref}(1.0)$ \\
\hline Confident & $0(0.0)$ & $97(100.0)$ & $120 \ldots(0.00-\ldots ; 0.996)$ & * \\
\hline \multicolumn{5}{|c|}{ Satisfaction supervision during clinical practice } \\
\hline Not satisfied & $7(15.9)$ & $37(84.1)$ & $\operatorname{Ref}(1.0)$ & $\operatorname{Ref}(1.0)$ \\
\hline Satisfied & $1(0.7)$ & $149(99.3)$ & $5.31(1.83-15.37 ; 0.007$ & $4.37(1.46-13.03 ; 0.008$ \\
\hline
\end{tabular}

${ }^{*}$ Multivariate analysis not run as only one factor was significant at univariate analysis. Satisfaction with supervision during clinical practiced was significantly associated with confidence to perform skills independently [UAOR 95\% CI; p-value $=5.31(1.83-15.37 ; 0.007)$, AOR $95 \%$ CI; p-value $=4.37(1.46$ 13.03; 0.008)]. 


\section{Acknowledgements}

We thank our funders, the Swedish International Development Agency (SIDA) for their financial support which enabled us to undertake and complete this research study.

We appreciate the Ministry of Health and the General Nursing Council, Zambia for giving us permission to conduct the study in the selected schools.

We also sincerely thank the tutors in the five schools who organized the students and assisted us with data collection: Ms Miyanda Nzobokela, Mr Wisdom Mwiiya, Ms Juliet Fyapeka, Ms Nchimunya Tembo and Ms Priscillah Champo.

Most importantly, we thank our respondents, the final year students in the schools where we conducted the research.

\section{Conflicts of Interest}

The authors declare no conflicts of interest regarding the publication of this paper.

\section{References}

[1] Sharma, B. (2014) Preparing Midwives as a Human Resource for Maternal Health: Pre-Service Education and Scope of Practice in Gujarat, India. Karolinska Institute, Stockholm.

[2] University of Zambia (2015) Nursing Curricular.

[3] Central Statistical Office (CSO) [Zambia], Ministry of Health (MOH) [Zambia], and ICF International (2014) Zambia Demographic and Health Survey 2013-14. Central Statistical Office, Ministry of Health, and ICF International, Rockville.

[4] UNFPA (2015) Recruiting Midwives as an Innovative Approach to Increasing Skilled Deliveries in Rural Zambia.

[5] Central Board of Health (2002) Integrated Guidelines for Frontline Health Workers. ZHP, USAID, Lusaka.

[6] ICAP at Colombia University (2016).

[7] Norman, M. and Hyland, T. (2003) The Role of Confidence in Lifelong Learning. Educational Studies, 29, 261-272. https://doi.org/10.1080/03055690303275

[8] Donovan, P. (2008) Confidence in Newly Qualified Midwives. British Journal of Midwifery, 16, 510-514. https://doi.org/10.12968/bjom.2008.16.8.30784

[9] Bandura, A. (1977) Self-Efficacy: Toward a Unifying Theory of Behavioural Change. Psychological Review, 84, 191-215. https://doi.org/10.1037/0033-295X.84.2.191

[10] Butler, M.M., Fraser, D.M. and Murphy, R.J.L. (2006) What Are the Essential Competencies Required of a Midwife at the Point of Registration? Midwifery, 24, 260-269. https://doi.org/10.1016/j.midw.2006.10.010

[11] Butler, M.M. (2001) Definitions of Midwifery Competence: Implications for Professional Learning. University of Nottingham, Nottingham.

[12] While, A.E., Fitzpatrick, J.M. and Roberts, J.D. (1998) An Exploratory Study of Similarities and Differences between Senior Students from Different Pre-Registration Nurse Education Courses. Nurse Education Today, 18, 190-198. https://doi.org/10.1016/S0260-6917(98)80078-6

[13] Sandall, J., Hatem, M., Devane, D., Soltani, H. and Gates, S. (2009) Discussions of 
Findings from a Cochrane Review of Midwife-Led versus Other Models of Care for Childbearing Women: Continuity, Normality and Safety. Midwifery, 25, 8-13. https://doi.org/10.1016/j.midw.2008.12.002

[14] Loudon, I. (1992) Death in Childbirth: An International Study of Maternal Care and Maternal Mortality 1800-1950. Clarendon Press, Oxford. https://doi.org/10.1093/acprof:oso/9780198229971.003.0016

[15] Renfrew, M.J., McFadden, A., Bastos, M.H., Campbell, J., Channon, A.A. and Cheung, N.F. (2014) Midwifery and Quality Care: Findings from a New Evidence-Informed Framework for Maternal and Newborn Care. The Lancet, 384, 1129-1145. https://doi.org/10.1016/S0140-6736(14)60789-3

[16] International Confederation of Midwives (2005) International Definition of the Midwife. https://www.internationalmidwives.org $>$ assests $>$ files

[17] Rooks, J.P. (1999) The Midwifery Model of Care. Journal of Nurse-Midwifery, 44, 370-374. https://doi.org/10.1016/S0091-2182(99)00060-9

[18] World Health Organization (2005) Make Every Mother and Child Count. World Health Organization, Geneva.

[19] International Confederation of Midwives (2013) Essential Competencies for Basic Midwifery Practice.

[20] Fleming, V. and Holmes, A. (2005) Basic Nursing and Midwifery Education Programmes in Europe. A Report to the World Health Organization Regional Office for Europe. World Health Organization, Copenhagen.

[21] UNFPA (2015) Consultant-Midwifery Education Pathway/UNFPA. https://www.unfpa.org?jobs>consultant-midwifery-education-pathway

[22] Maine, D. (2007) Detours and Shortcuts on the Road to Maternal Mortality Reduction. The Lancet, 370, 1380-1382. https://doi.org/10.1016/S0140-6736(07)61580-3

[23] Koblinsky, M., Matthews, Z., Hussein, J., Mavalankar, D., Mridha, M.K., Anwar, I., et al. (2006) Going to Scale with Professional Skilled Care. The Lancet, 368, 1377-1386. https://doi.org/10.1016/S0140-6736(06)69382-3

[24] Utz, B., Siddiqui, G., Adegoke, A. and Broek, N.V.D. (2013) Definitions and Roles of a Skilled Birth Attendant: A Mapping Exercise from Four South-Asian Countries. Acta Obstetriciaet Gynecological Scandinavica, 92, 1063-1069. https://doi.org/10.1111/aogs.12166

[25] World Health Organization, UNICEF, UNFPA, the World Bank (2011) Trends in Maternal Mortality 1910-2010. WHO, UNICEF, UNFPA, The World Bank Estimates.

[26] Mensa, I. (2014). http://www.researchgate.net

[27] Basavanthappa, B.T. (2007) Nursing Research. Jaypee Brothers Medical Publishers, New Delhi.

[28] Yigzaw, T., Ayalew, F., Kim, Y.-M., Gelagay, M., Dejene, D., Gibson, H., Teshome, A., Broerse, J. and Stekelenburg, J. (2015) How Well Does Preservice Education Prepare Midwives for Practice: Competence Assessment of Midwifery Students at the Point of Graduation in Ethiopia. BMC Medical Education, 15, 130.

https://www.ncbi.nlm.nih.gov/pmc/articles/PMC4536794 https://doi.org/10.1186/s12909-015-0410-6

[29] Katowa-Mukwato, P., Chapima, F., Nambala-Sianchapa, B. and Mwiinga-Kalusopa, V. (2017) Learning Styles and Intelligence Types versus Academic Performance of Nursing Students at the University of Zambia. Journal of Nursing Education and Practice, 7, 83-90. https://doi.org/10.5430/jnep.v7n10p83 
[30] Bweupe, N., Ngoma, C.M. and Sianchapa, B. (2018) Clinical Supervision of Midwifery Students at University Teaching Hospital School of Nursing and Midwifery in Lusaka, Zambia. Open Journal of Nursing, 8, 372-389.

https://doi.org/10.4236/ojn.2018.86030

[31] Lendahls, L. and Oscarsson, M.G. (2017) Midwifery Students' Experience of Simulation and Skills Training. Nurse Education Today, 50, 12-16.

https://pubmed.ncbi.nlm.nih.gov/28006699

https://doi.org/10.1016/j.nedt.2016.12.005 